\title{
The Seven-Year Preliminary Results of Brachytherapy with Iodine-125 Seeds for Localized Prostate Cancer Treated At a Brazilian Single-Center
}

\author{
Carlos A. S. Franca, Sergio L. Vieira, Antonio J. S. Bernabe, Antonio B. R. Penna \\ Department of Radiation Oncology, Brazilian Institute of Oncology (IBO), Radioterapia Botafogo, \\ Rio de Janeiro, Brazil
}

\begin{abstract}
Objective: To report the seven-year preliminary results of a single-center on brachytherapy with Iodine-125 seeds, used in combination with external beam radiotherapy in selected patients with localized prostate cancer (T1-T2).

Materials and Methods: All 105 patients treated by brachytherapy with Iodine-125 seeds, from January/1998 to December/ 2004, were retrospectively analyzed. The prescribed dose was $144 \mathrm{~Gy}$ at the periphery of the prostate for isolated brachytherapy, and $110 \mathrm{~Gy}$ for the combination with external beam radiotherapy. The external beam radiotherapy dose was $45 \mathrm{~Gy}$, at the prostatic bed. Neoadjuvant hormone therapy was indicated for selected patients, who received luteinizing hormone-releasing hormone (LH-RH) and/or antiandrogens. For definition of biochemical relapse, it was adopted the American Society for Therapeutic Radiology and Oncology consensus.

Results: Of the 105 patients treated, 90 were followed for a mean period of 70 months. Biochemical disease control was achieved in 62 (69\%) and biochemical recurrence was manifested in 28 (31\%). The analysis of each risk group showed biochemical disease control rates of 79\%,71\% and 52\% in the low, intermediate and high risk groups, respectively. The mean time for biochemical recurrence was 22 months. Genitourinary acute toxicity was classified as grade 0-2 (RTOG) in 88.5\% and in $94.2 \%$ for the late toxicity (RTOG/EORTC). Gastrointestinal acute toxicity was graded as 0-2 (RTOG) in 100\% and in $97.7 \%$ for the late morbidity. No grade 5 was detected.

Conclusions: Brachytherapy with Iodine-125 seeds is an effective alternative treatment for early stage prostatic cancer, with good biochemical disease control rates and low to moderate toxicity. The best results were obtained in low and intermediate risk patients.
\end{abstract}

Key words: prostatic neoplasms; prostate-specific antigen; brachytherapy; iodine radioisotopes Int Braz J Urol. 2007; 33: 752-63

\section{INTRODUCTION}

In Brazil, there are 51 cases of prostate cancer out of every 100,000 people, per year. In developed countries, prostate cancer represents $15.3 \%$ of all cancer cases, compared to a rate of $4.3 \%$ in developing countries. The recent rise in the incidence is probably due to the diagnosis of new cases among asymptomatic individuals, after the increased use of prostate specific antigen (PSA) determination (1).

Localized prostate cancer can be successfully treated by surgery (radical prostatectomy), external 
beam radiotherapy or brachytherapy (2). According to recent literature, the biochemical control rates attained by brachytherapy with Iodine- 125 seeds are similar to those of radical prostatectomy and external beam radiotherapy (3).

Brachytherapy with Iodine-125 seeds has been increasingly used due to technological advances in transrectal ultrasonography, availability of radioactive iodine sources adapted for implantation in the prostatic gland and to the development of computerized planning programs for this therapeutic method (4).

One of the main advantages of brachytherapy is its conformational property, concentrating high doses of radiation inside the target volume and a rapid fallof in adjacent structures, such as rectum and bladder (5).

Other benefits of this technique are the short time to be performed, hospitalization for only 24 hours and low to medium intensity side effects, allowing a quick return of the patient to normal activities (6).

One of the radioisotopes used in prostate brachytherapy is Iodine-125, which has a half-life of 60 days and emits gamma rays of $27 \mathrm{Kev}$ (6). Sources are permanently implanted into the gland, without risk of radiation to the general population, due to emission of low energy photons.

Intermediate or high risk patients may be submitted to external beam radiotherapy before brachytherapy, to destroy possible extraprostatic neoplastic cells situated beyond the reach of radiation emitted by Iodine-125 seeds (7).

Although the indication for neoadjuvant hormone therapy is still controversial, many publications have been divulged concerning its use $(8,9)$. Prescription of neoadjuvant hormone therapy aimed at reducing prostatic volume, when the gland is over 50g (cytoreduction), and destroying malignant cells, acting as an antineoplastic agent (10).

The objectives of this paper are to evaluate the biochemical disease control after seven years follow-up, the immediate acute side effects and the late toxicity of 90 patients with localized prostate cancer (T1-T2) treated by brachytherapy with Iodine-125 seeds, in association with external beam radiotherapy in selected patients.

\section{MATERIALS AND METHODS}

From January/1998 to December/2004, 105 patients with localized prostate cancer, referred from different urologists, were treated by brachytherapy with Iodine-125 seeds, and were retrospectively analyzed, taking into consideration the value of initial PSA (iPSA), Gleason's score and clinical stage (TNM) (11). iPSA is defined as the latest value of total PSA, measured before applying any treatment.

Patients were classified into three risk group categories, also adopted by Seattle Prostate Institute (12), that, based on prognostic factors such as iPSA, Gleason score and clinical stage (TNM) (11), evaluate the risk of biochemical recurrence after any type of treatment. The risk groups are described as low risk: iPSA $\leq 10 \mathrm{ng} / \mathrm{mL}$, Gleason $<7$ and clinical stage < $\mathrm{T} 2 \mathrm{c}$, intermediate risk: iPSA $>10 \mathrm{ng} / \mathrm{mL}$ or Gleason $\geq$ 7 or clinical stage $\geq \mathrm{T} 2 \mathrm{c}$ (one risk factor with a higher value than those for the low risk), and high risk: presence of two or more risk factors with higher values than those for the low risk.

There were $33(37 \%)$ patients classified as low risk, 34 (38\%) as intermediate risk and 23 (25\%) as high risk.

Isolated brachytherapy was applied in all 33 low risk, in 27/34 intermediate and in 15/23 high risk patients. Combination of brachytherapy with external radiation was prescribed for $7 / 34$ intermediate and 8/ 23 high risk patients.

Brachytherapy was performed in three sequential stages: preplanning, implantation of radioactive sources and post-planning dosimetry.

Pre-planning consisted of prostate volumetric study, performed through transrectal ultrasonography with a GE ${ }^{\mathrm{TM}} / 3200$ Advantage II / RT ultrasound machine, equipped with a specific module for prostate brachytherapy. Axial images of the gland in $0.5 \mathrm{~cm}$ equidistant planes, from the base until the apex of the prostate were recorded and transferred to a computer loaded with a PROWESS $2.0^{\mathrm{TM}}$ program, which supplied technical data for the procedure.

Implantation of seeds were performed in the operating room, under peridural anesthesia, introducing each source in strategic positions previously determined by the computer, driven by a template with 
alpha-numeric grading that allowed placement of each radioactive source into pre-determined coordinates. Pre-loaded needles with stranded seeds were used (RapidStrand $^{\mathrm{TM}}$, ONCURA, Plymouth Meeting, PA, USA).

Post-planning dosimetry was performed to evaluate technical quality of the implant and to quantify doses of radiation delivered to prostate, bladder and adjacent rectum. This procedure begins with a pelvic computerized tomography, where the prostate, rectum and bladder were identified, followed by images transference to a computer for calculation of final doses of radiation in these organs, as well as others dosimetric values of the implant such as $\mathrm{V}_{100}$, which is the volume of prostate that received $100 \%$ of the radiation dose and the $\mathrm{D}_{90}$, which is the dose received by $90 \%$ of the prostate. The prescribed doses were the same suggested by American Association of Physicists in Medicine (AAPM) Task Group 43 (TG43) (13), that recommends 144 Gy at the prostate periphery for isolated brachytherapy and $110 \mathrm{~Gy}$ when associated to external beam radiation therapy.

External beam treatment planning began with a pelvic computerized tomography, for identification of the target volume, bladder and rectum. After defining the ideal positioning of each radiation field, confirmation of their precise position were made through portal films taken by the treatment machine. The linear accelerator used for external beam radiotherapy was a Siemens ${ }^{\mathrm{TM}}$, Mevatron model, with $6 \mathrm{MeV}$ photon energy. The total dose prescribed was $45 \mathrm{~Gy}$, restricted to prostatic bed, applied in daily fractions of $1.8 \mathrm{~Gy}$, over five weeks.

Neoadjuvant hormone therapy, with LH-RH agonists and/or anti-androgenic, was only used in patients with prostatic volume above $50 \mathrm{~g}$, prescribed by the assistant urologist and interrupted immediately after brachytherapy, in all cases. Neoadjuvant hormone therapy was applied in 11/33 low risk, in 20/34 intermediate and in 14/23 high risk patients.

For definition of biochemical relapse, it was adopted the American Society for Therapeutic Radiology and Oncology (ASTRO) (14) consensus, which establishes as treatment failure, three successive increases of total PSA, measured with intervals of 4 to 6 months or the beginning of any salvage therapy, with recurrence occurring on the date corresponding to the midpoint between the nadir PSA (nPSA) date and that of the first PSA rise (14). nPSA is the lowest value of total PSA reached after treatment.

It was assumed as acute toxicity the signs and symptoms that appeared up to 120 days after treatment and as late toxicity the side effects manifested after this date (15).

The Radiation Therapy Oncology Group (RTOG) system was used for evaluation of acute toxicity of brachytherapy in gastrointestinal (GI) and in genitourinary (GU) tracts (15). To analyze late toxicity, the RTOG/European Organization for Research and Treatment of Cancer (EORTC) (15) criteria was used (Appendix-1).

In this study, toxicities were evaluated during personal interviews performed by the physician in charge every 4-6 months after implantation, who recorded PSA values, the physical and laboratory findings. It was not possible to evaluate toxicity in three patients.

The statistical method applied was the chisquare test for the categorical variables and the tStudent test for the continuous variables. Actuarial three and five years biochemical disease free survival (BDFS) and the possible influence of certain factors (external beam radiotherapy, neoadjuvant hormone therapy, risk group category) on biochemical disease control were analyzed by the Kaplan-Meier method and the log-rank test. A significance level of 5\% probability $(\mathrm{p}<0.05)$ and a confidence interval with 95\% (CI95) probability were adopted. Statistic analysis was performed through the SPSS program for Windows version 13.0 (SPSS Inc ${ }^{\mathrm{TM}}$, Chicago).

This study was approved by the Ethics Research Committee of the Clementino Fraga Filho University Hospital of Rio de Janeiro Federal University, carrying out determinations set by the National Council of Ethics in Research and Resolution 196/96 of the National Health Council.

\section{RESULTS}

We analyzed 105 patients, and 90 cases were selected for evaluation. There were 12 deaths, not 
related to the prostate disease, and three patients were lost to follow-up.

Mean age was 68 years $(46$ - 90; 95CI: 66.3 - 69.48), and the mean iPSA was $13.65 \mathrm{ng} / \mathrm{mL}$ (3.2 70; 95CI: 10.99 - 16.32).

Median Gleason score was 6 (2 - 9), with $80 \%$ showing Gleason from 2 to 6 (72 patients) and $20 \%$ with Gleason $>6$ (18 patients).

77 patients $(85.5 \%)$, were staged as T2b-T2c and 13 patients (14.5\%) as T1c-T2a.

Biochemical disease control was achieved in $62(69 \%)$ of the 90 patients, after a mean follow-up period of 70 months (25-108; 95CI: 63.18 - 76.62). Biochemical disease control according to risk group category can be seen in Table- 1 . The mean time for biochemical recurrence was 22 months $(15-66$; 95CI: 14,48 - 29,45).

Evaluation of the interference from various factors (risk groups, age, iPSA value, Gleason score, clinical stage, use of neoadjuvant hormone therapy, association with external beam radiotherapy, $\mathrm{V}_{100}$, $\mathrm{D}_{90}$ ) in the biochemical control rate showed that the risk group classification influenced the results, becoming evident that the lower the risk group, the greater the chances of therapeutic success. Biochemical disease control rate was $79 \%$ for low risk patients, $71 \%$ for intermediate risk and $52 \%$ for the high risk $(\mathrm{p}=0.039)$.

Actuarial global analysis showed that mean iPSA in patients who attained biochemical disease control was $10.66 \mathrm{ng} / \mathrm{mL}$ (3.20 - 70. 95CI: 8.13 - 13.18) and $20.29 \mathrm{ng} / \mathrm{mL}$ for the biochemical recurrence group (4.80 - 65. 95CI: $14.22-26.35)$, leading to the conclusion that the lower the iPSA value, the higher the biochemical disease control rate $(\mathrm{p}=0.001)$.

Association of Iodine-125 seeds brachytherapy with external beam radiotherapy, used for intermediate and high risk patients, showed a positive result; out of 15 patients submitted to this combined treatment, 93\% (14) achieved biochemical control, against $52.4 \%$ (22) in those who received isolated brachytherapy $(\mathrm{p}=0.05)$.

Factors that had no statistically significant influence in the results were age $(p=0.412)$, Gleason $(p=0.095)$, clinical stage $(p=0.228)$ and neoadjuvant hormone therapy $(\mathrm{p}=0.070)$.
Table 1 - Biochemical disease control according the risk groups.

\begin{tabular}{lcc}
\hline $\begin{array}{l}\text { Risk } \\
\text { Groups }\end{array}$ & N & $\begin{array}{c}\text { Biochemical Disease } \\
\text { Control - N }(\%)\end{array}$ \\
\hline Low & 33 & $26(79 \%)$ \\
Intermediate & 34 & $24(71 \%)$ \\
High & 23 & $12(52 \%)$ \\
\hline
\end{tabular}

The mean $\mathrm{V}_{100}$ was $82.9 \%(46.2$ - 99; 95CI: 79.2 - 86.7) and mean $\mathrm{D}_{90}$ was $138.2 \mathrm{~Gy}(100.9 \mathrm{~Gy}$ 170 Gy; 95CI: 133 Gy - 144 Gy). $V_{100}$ and $D_{90}$ did not show any influence in the results with $p$ values of 0.365 and 0.297 respectively.

Analysis performed discriminately for different risk groups showed that low risk group did not suffer influence of any factors above-mentioned.

However, there was a statistically significant influence of iPSA and $\mathrm{D}_{90}$ in the results of intermediate risk category where patients with biochemical disease control had a mean iPSA of $9.14 \mathrm{ng} / \mathrm{mL}(3.50$ - 17. 95CI: 7.43 - 10.85) while in biochemical recurrences the mean iPSA was $22.19 \mathrm{ng} / \mathrm{mL}(7.40-65.95 \mathrm{CI}$ : 10.07 - 34.31), with $\mathrm{p}=0.001$. Mean $\mathrm{D}_{90}$ was higher in patients with biochemical disease control - 141.6 Gy (95CI: 132.9 Gy $-149.3 \mathrm{~Gy}$ ) than in those with biochemical recurrence - 111.9 Gy (95CI: 87.8 Gy $136 \mathrm{~Gy}$ ), where $\mathrm{p}=0.041$.

In high risk category, the association with external beam radiotherapy had statistically significant influence, obtaining $87.5 \%$ biochemical disease control in cases submitted to the combined treatment against $33.4 \%$ in those who received isolated brachytherapy $(\mathrm{p}=0.013)$.

BDFS for three and five years were $76 \% \mathrm{e}$ $70 \%$, respectively (Figure-1). Five years BDFS, stratified by risk groups were $78 \%, 62.5 \%$ e $55 \%$ (p $=0.53$ ) for low, intermediate and high risk, respectively (Figure-2). Combination of brachytherapy with external beam radiotherapy gave $76.7 \%$ five years BDFS, while in the brachytherapy alone group, the rate was $40.7 \%$ ( $p<0.05$ ) (Figure-3). Neoadjuvant hormone therapy did not improve the 5 years BDFS. 


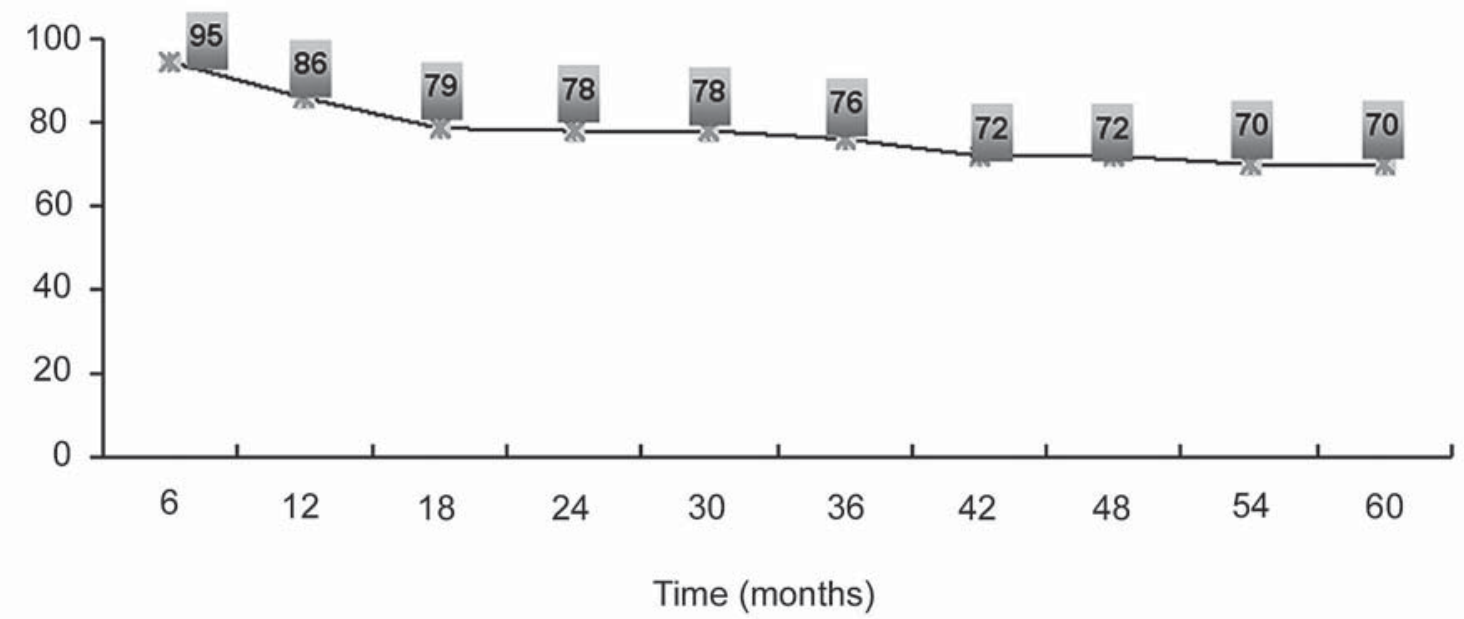

Figure 1-Biochemical disease free incidence.

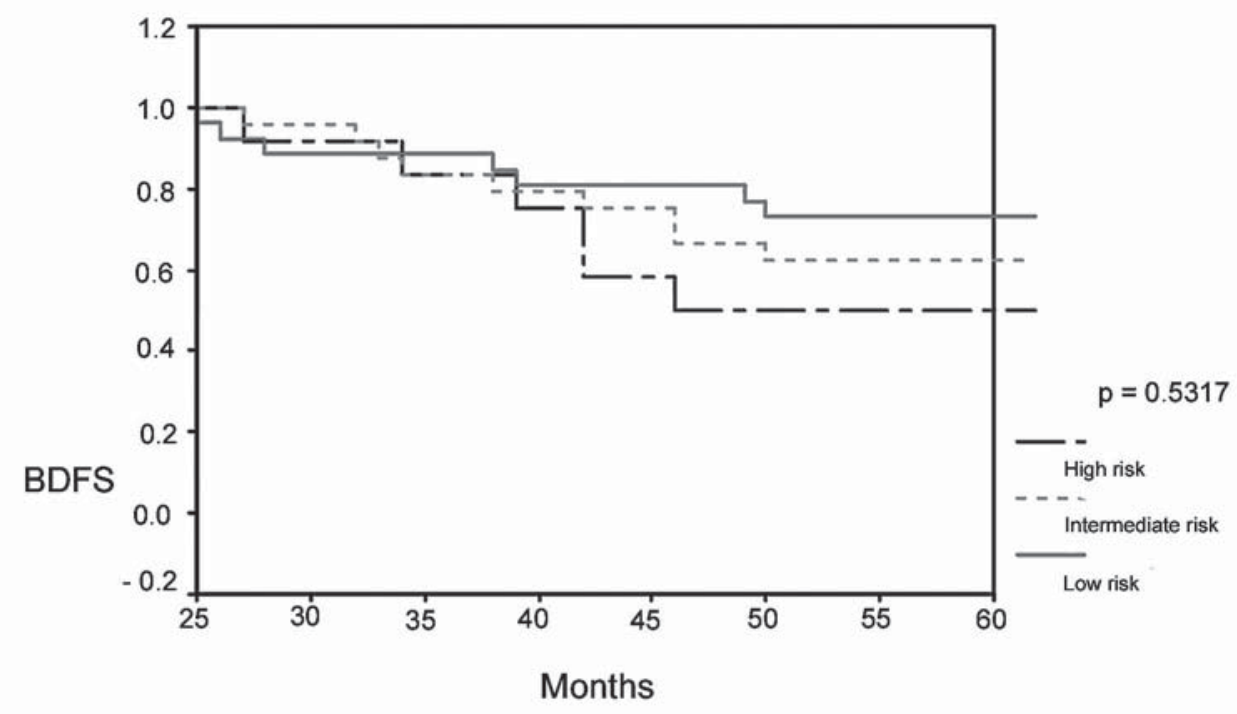

Figure 2 - Five years biochemical disease free survival (BDFS) for risk groups.

In patients submitted to this therapy a BDFS rate of $68 \%$, was obtained against $71 \%$ in the untreated group $(\mathrm{p}=0.88)$ (Figure-4).

Iodine-125 seeds brachytherapy presented low morbidity, with acute and late toxicity characterized by mild to moderate symptoms, controlled by palliative medication, allowing patients to perform normal activities in most cases. Tables- 2 and 3 relate degrees of toxicities in GU and GI tracts.

It can be conclude that, most patients had low levels of acute and late toxicities (grades 0,1 e 2) with a predominance of urinary symptoms (grades 1 and 2) in the first four months after brachytherapy $(67.8 \%)$ over GI complains (26.4\%). 


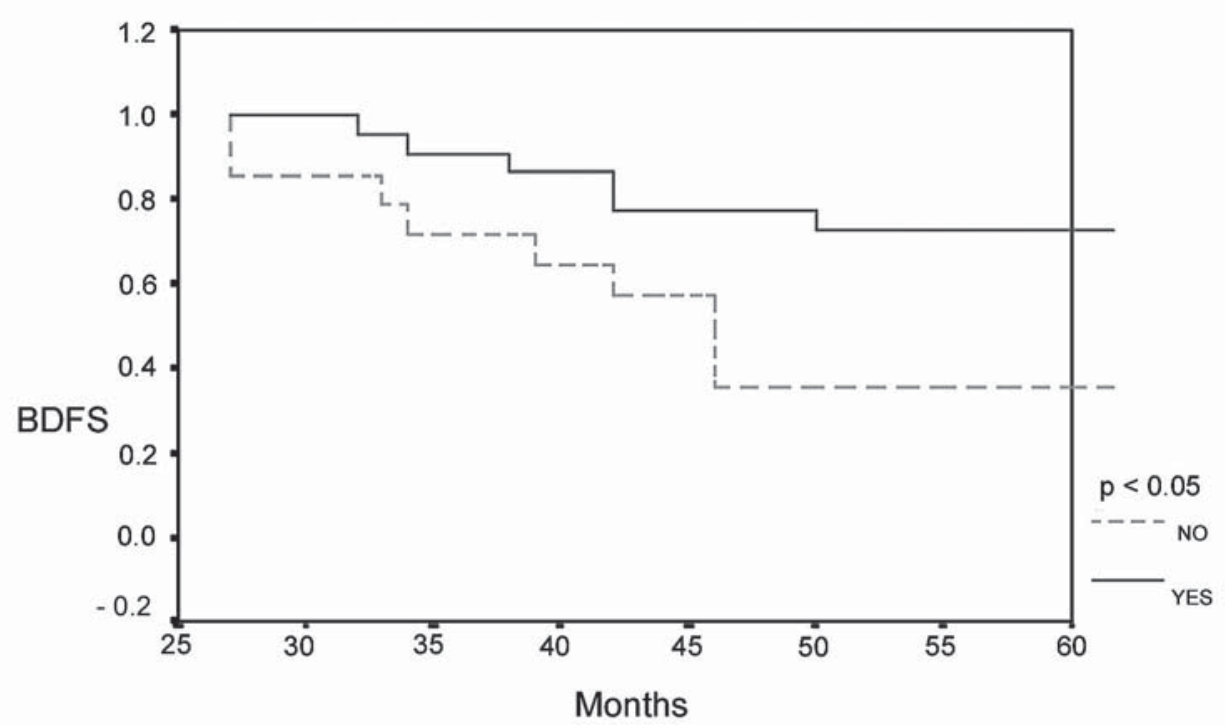

Figure 3 - Five years biochemical disease free survival (BDFS) for the combination of brachytherapy with external beam radiotherapy.

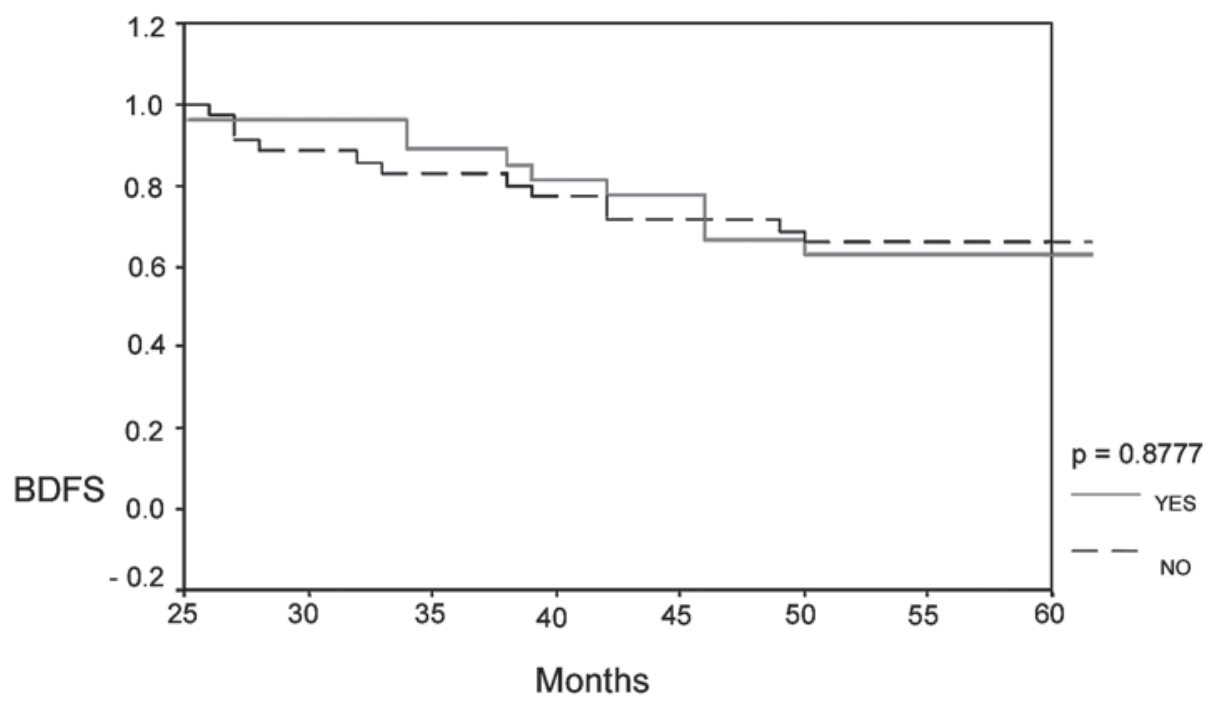

Figure 4 - Five years biochemical disease free survival (BDFS) with neoadjuvant hormone therapy.

Late toxicity was also of low intensity and frequency, requiring palliative medication in 8 patients and therapeutic intervention in 7.

The association with external beam radiotherapy or the use of neoadjuvant hormone therapy did not have statistically significant interference in GU / GI acute and late toxicities rates (Table-4).

\section{COMMENTS}

The parameter used for evaluation of response to treatment and for comparison with other authors/ results was the biochemical PSA recurrence, defined by ASTRO consensus (14).

Although radical prostatectomy offers high biochemical disease control rates, similar results can 
Table 2 - Acute toxicity (RTOG).

\begin{tabular}{lccllll}
\hline Grade & \multicolumn{1}{c}{} & \multicolumn{1}{c}{$\mathbf{1}$} & \multicolumn{1}{c}{$\mathbf{2}$} & $\mathbf{3}$ & $\mathbf{4}$ & $\mathbf{5}$ \\
\hline GU & $18(20.7 \%)$ & $50(57.5 \%)$ & $9(10.3 \%)$ & $6(6.9 \%)$ & $4(4.6 \%)$ & 0 \\
GI & $64(73.6 \%)$ & $22(25.3 \%)$ & $1(1.1 \%)$ & 0 & 0 & 0 \\
\hline
\end{tabular}

$G U=$ genitourinary; $G I=$ gastrointestinal .

Table 3 - Late toxicity (RTOG/EORTC).

\begin{tabular}{lcccccc}
\hline Grade & $\mathbf{0}$ & $\mathbf{1}$ & $\mathbf{2}$ & $\mathbf{3}$ & $\mathbf{4}$ & $\mathbf{5}$ \\
\hline GU & $68(78.2 \%)$ & $11(12.6 \%)$ & $3(3.4 \%)$ & $3(3.4 \%)$ & $2(2.3 \%)$ & 0 \\
GI & $79(90.8 \%$ & $1(1.1 \%)$ & $5(5.7 \%)$ & $2(2.3 \%)$ & 0 & 0 \\
\hline
\end{tabular}

$G U=$ genitourinary; $G I=$ gastrointestinal .

Table 4 - Toxicity significance.

\begin{tabular}{lcccc}
\hline \multicolumn{4}{c}{ External Beam Radiotherapy } & \multicolumn{2}{c}{ Neoadjuvant Hormone Therapy } \\
\hline & Acute & Late & Acute & Late \\
GU & $\mathrm{p}=0.327$ & $\mathrm{p}=0.603$ & $\mathrm{p}=0.055$ & $\mathrm{p}=0.805$ \\
GI & $\mathrm{p}=0.775$ & $\mathrm{p}=0.621$ & $\mathrm{p}=0.619$ & $\mathrm{p}=0.750$ \\
\hline
\end{tabular}

$G U=$ genitourinary $; G I=$ gastrointestinal .

be found in literature with external beam radiotherapy or Iodine-125 seeds brachytherapy (16-18).

A survey of 90 patients with localized prostate cancer, treated by brachytherapy with Iodine-125 seeds in this clinic, showed biochemical disease control similar to those published by other centers, which achieved rates varying from $66-88 \%$, for 5 to 12 years of follow-up $(3,4,10,12)$.

Analysis of results stratified by risk groups showed that low risk patients reached biochemical control in $79 \%$, intermediate risk in $71 \%$ and high risk in $52 \%$. Equivalent results were published by Blasko et al. (16), who reported biochemical control of $94 \%$, $82 \%$ and $65 \%$ for low, intermediate and high risk cohorts respectively. Izard et al. (19) published biochemical control after three years, of $100 \%, 97 \%$ e $81 \%$ for low, intermediate and high risk groups, respectively, with 93\% BDFS. BDFS achieved in this work, after three years of surveillance, was $76 \%$, while after 5 years, the values were $78 \%, 62.5 \%$ and $55 \%$ for low, intermediate and high risk groups. Similar results were obtained by Kwok et al. (20) who refer BDFS in $85 \%, 63 \%$ and $24 \%$, and by Guedea et al. (21), who obtained $92 \%, 74 \%$ and $55 \%$, for low, intermediate and high risk groups, respectively.

Analysis of the relation between iPSA values and the probability of biochemical disease recurrence showed that the higher the iPSA the greater the chance of biochemical recurrence, which was also described by Sylvester et al. (12), who achieved biochemical control rates of $76.4 \%$ for iPSA $\leq 10 \mathrm{ng} / \mathrm{mL}$ and $52.8 \%$ for iPSA > $20 \mathrm{ng} / \mathrm{mL}$. 
Stock et al. (22) demonstrated that the dose delivered in the prostate is a significant predictive factor for biochemical recurrence, as patients who receive more than $140 \mathrm{~Gy}$ of the total dose in $90 \%$ of the prostate $\left(D_{90}>97 \%\right)$ attained biochemical control in $92 \%$ compared to $62 \%$ among those with $D_{90}<$ $140 \mathrm{~Gy}$. In the present study, $\mathrm{D}_{90}$ only had statistically significance in intermediate risk group, when evaluated isolatedly. Actuarial global analysis, however, showed that $\mathrm{D}_{90}$ was not statistically significant.

Jani et al. (2) published evident benefits with the combination of external beam radiotherapy and brachytherapy for intermediate and high risk patients, where biochemical disease control was $70 \%$ against $50 \%$ for those submitted to isolated brachytherapy. Our results also confirm the advantage of combined treatment, especially for high risk patients, who achieved biochemical control in $87.5 \%$ against $33.4 \%$ in those who received isolated brachytherapy.

The main purpose for neoadjuvant hormone therapy is the reduction of prostate size when volume is over $50 \mathrm{~g}(8,9)$. This was also the rational for its prescription in this work. Its antineoplastic property still presents questionable effects (10), with controversial application (23). This study was unable to show any improvement in biochemical disease control rates with the use of neoadjuvant hormone therapy.

Data from literature demonstrate that morbidity of brachytherapy with Iodine- 125 seeds is similar to those of external beam radiotherapy and radical prostatectomy $(23,24)$. The GU acute toxicity was of low intensity (grade 0-2 RTOG) and easily controlled in $88.5 \%$. Singh et al. (24) also related low acute GU toxicity (grade $0-2$ ) among $91 \%$ and in $100 \%$ for GI tract, with no RTOG grade 3 or 4 . Izard et al. (19) also published low rates of acute toxicity, obtaining grade $0-2$ in $97.4 \%$, grade 3 in $2.6 \%$ and no grade 4 .

Zapatero et al. (25) e Valicenti et al. (26) did not found any relation between neoadjuvant hormone therapy and acute GI toxicity, however, there was a rise in GU acute toxicity. This work also did not report any increase in acute toxicity of the GI, but a slight rise in that of $\mathrm{GU}$, although not reaching statistic significance.
The combination with external beam radiotherapy did not increase acute and late toxicities of GU and GI in any significant way, which is in accordance with Gelblum et al. $(27,28)$.

Further work-up is being prepared with higher number of patients for later analysis, and for comparison of results employing the ASTRO and PHOENIX (29) failure definition. Recent studies suggest the PHOENIX consensus as the best definition of biochemical disease recurrence $(30,31)$.

\section{CONCLUSION}

Brachytherapy with Iodine-125 seeds is currently accepted as an alternative treatment for localized prostate cancer. Its biochemical disease control results are similar to those of traditional therapeutic methods, with low to moderate morbidity for the GU and GI tracts.

The best results are attained in low and intermediate risk groups. In high risk category, brachytherapy also shows competitive efficacy, requiring further studies to improve results in this bad prognostic group.

Clinicopathological data with greatest influence in biochemical relapse rates was iPSA value and the classification in risk groups according to the prognostic factors present in each patient.

It can be concluded that, although our preliminary results might have limited statistical power due to small number of patients, they are in accordance with the current literature.

\section{ACKNOWLEDGEMENTS}

This work was sponsored by the Brazilian Institute of Oncology (IBO). Jennifer Uribe was responsible for the installation of Iodine-125 seeds brachytherapy in Brazil.

\section{CONFLICT OF INTEREST}

None declared. 
Appendix -1

\begin{tabular}{|c|c|c|c|c|}
\hline $\begin{array}{l}\text { Acute RTOG } \\
\text { scale }\end{array}$ & Grade 1 & Grade 2 & Grade 3 & Grade 4 \\
\hline GU & $\begin{array}{c}\text { Frequency of } \\
\text { urination or nocturia } \\
\text { twice pretreatment } \\
\text { habit/dysuria or } \\
\text { urgency not } \\
\text { requiring medication. }\end{array}$ & $\begin{array}{l}\text { Frequency of urination } \\
\text { is less frequent than } \\
\text { every hour (day: } 12-16 \\
\text { times; nocturia 5-8 } \\
\text { times)/dysuria, } \\
\text { urgency, bladder } \\
\text { spasm requiring local } \\
\text { anesthetic. }\end{array}$ & $\begin{array}{c}\text { Frequency of urination } \\
\text { is more frequent than } \\
\text { every hour (day }>16 \\
\text { times; nocturia }>8 \text { times)/ } \\
\text { dysuria, bladders spasm, } \\
\text { urgency requiring } \\
\text { frequent regular } \\
\text { narcotic/ gross } \\
\text { hematuria. }\end{array}$ & $\begin{array}{c}\text { Hematuria requiring } \\
\text { transfusion/ } \\
\text { obstruction not due } \\
\text { to clots/ ulceration/ } \\
\text { necrosis. }\end{array}$ \\
\hline GI & $\begin{array}{l}\text { Increased frequency } \\
\text { or change in quality } \\
\text { of bowel habits not } \\
\text { requiring medication/ } \\
\text { rectal discomfort not } \\
\text { requiring analgesics. }\end{array}$ & $\begin{array}{c}\text { Diarrhea requiring } \\
\text { parasympatholytic } \\
\text { drugs/ mucous } \\
\text { discharge not } \\
\text { necessitating sanitary } \\
\text { pads/ rectal or } \\
\text { abdominal pain } \\
\text { requiring analgesics. }\end{array}$ & $\begin{array}{c}\text { Diarrhea requiring } \\
\text { parenteral support/ } \\
\text { severe mucous or blood } \\
\text { discharge necessitating } \\
\text { sanitary pads/ } \\
\text { abdominal distension. }\end{array}$ & $\begin{array}{c}\text { Obstruction, fistula, } \\
\text { or perforation; GI } \\
\text { bleeding requiring } \\
\text { transfusion; } \\
\text { abdominal pain or } \\
\text { tenesmus requiring } \\
\text { tube decompression } \\
\text { or bowel diversion. }\end{array}$ \\
\hline $\begin{array}{l}\text { Late RTOG/ } \\
\text { EORTC scale }\end{array}$ & Grade 1 & Grade 2 & Grade 3 & Grade 4 \\
\hline GU & $\begin{array}{c}\text { Frequency during } \\
\text { day } 0,5-1 \mathrm{~h} \text {; nocturia } \\
\text { 2-3; slight dysuria or } \\
\text { microscopic } \\
\text { hematuria requiring } \\
\text { no medication, } \\
\text { bladder capacity }> \\
300 \text { cc. }\end{array}$ & $\begin{array}{l}\text { Frequency during day } \\
\text { 1-2h; nocturia 4-6; } \\
\text { moderate dysuria or } \\
\text { intermittent hematuria } \\
\text { requiring medication, } \\
\text { bladder capacity } 150- \\
300 \text { cc. }\end{array}$ & $\begin{array}{c}\text { Frequency during day } \\
>2 \mathrm{~h} \text {; nocturia }>6 \text {; severe } \\
\text { dysuria, frequent } \\
\text { hematuria, bladder } \\
\text { capacity } 100-150 \mathrm{cc} \text {. }\end{array}$ & $\begin{array}{l}\text { Necrosis, severe } \\
\text { hemorrhagic } \\
\text { cystitis, bladder } \\
\text { capacity < } 100 \mathrm{cc} \text {. }\end{array}$ \\
\hline GI & $\begin{array}{l}\text { Mild diarrhea, mild } \\
\text { cramping, bowel } \\
\text { movements 2-5/day, } \\
\text { slight rectal } \\
\text { discharge or } \\
\text { bleeding. }\end{array}$ & $\begin{array}{l}\text { Moderate diarrhea, } \\
\text { intermittent severe } \\
\text { cramping, bowel } \\
\text { movements }>5 / \text { day, } \\
\text { rectal discharge, } \\
\text { intermittent bleeding. }\end{array}$ & $\begin{array}{l}\text { watery diarrhea, } \\
\text { obstruction requiring } \\
\text { surgery, bleeding } \\
\text { requiring surgery. }\end{array}$ & $\begin{array}{l}\text { Necrosis, } \\
\text { perforation. }\end{array}$ \\
\hline
\end{tabular}




\section{REFERENCES}

1. INCA. Estimativa 2006: Incidência de câncer no Brasil. Rio de Janeiro. 2005; p. 34. http://www.inca.gov.br/ estimativa/2006/versaofinal.pdf.

2. Jani AB, Feinstein JM, Pasciak R, Krengel S, Weichselbaum RR: Role of external beam radiotherapy with low-dose-rate brachytherapy in treatment of prostate cancer. Urology. 2006; 67: 1007-11.

3. Potters L, Morgenstern C, Calugaru E, Fearn P, Jassal A, Presser J, et al.: 12-year outcomes following permanent prostate brachytherapy in patients with clinically localized prostate cancer. J Urol. 2005; 173 : 1562-6.

4. Merrick GS, Butler WM, Galbreath RW, Lief JH: Fiveyear biochemical outcome following permanent interstitial brachytherapy for clinical T1-T3 prostate cancer. Int J Radiat Oncol Biol Phys. 2001; 51: 41-8.

5. Blasko JC, Ragde H, Grimm PD, Cavanagh W: Prostate brachytherapy: importance of technique. J Clin Oncol. 1996; 14: 1965-7.

6. Hanriot RM, Salvajoli JC: Tumores de próstata. In: Salvajoli JC, Souhami L, Faria SL. Radioterapia em Oncologia. 1ª Ed. MEDSI, 1999; pp. 671-4.

7. Lee WR, DeSilvio M, Lawton C, Gillin M, Morton G, Firat S, Baikadi M, Kuettel M, Greven K, Sandler H: A phase II study of external beam radiotherapy combined with permanent source brachytherapy for intermediaterisk, clinically localized adenocarcinoma of the prostate: preliminary results of RTOG P-0019. Int J Radiat Oncol Biol Phys. 2006; 64: 804-9.

8. Bolla M, Gonzalez D, Warde P, Dubois JB, Mirimanoff RO, Storme G, et al.: Improved survival in patients with locally advanced prostate cancer treated with radiotherapy and goserelin. N Engl J Med. 1997; 337 : 295-300.

9. Pilepich MV, Winter K, Lawton CA, Krisch RE, Wolkov HB, Movsas B, et al.: Androgen suppression adjuvant to definitive radiotherapy in prostate carcinoma-longterm results of phase III RTOG 85-31. Int J Radiat Oncol Biol Phys. 2005; 61: 1285-90.

10. Stock RG, Cesaretti JA, Stone NN: Disease-specific survival following the brachytherapy management of prostate cancer. Int J Radiat Oncol Biol Phys. 2006; 64: 810-6.

11. TNM: Classificação de tumores malignos. (6 ed.), Rio de Janeiro, INCA. 2004; pp. 190-3.

12. Sylvester JE, Blasko JC, Grimm PD, Meier R, Malmgren JA: Ten-year biochemical relapse-free survival after external beam radiation and brachytherapy for localized prostate cancer: the Seattle experience. Int J Radiat Oncol Biol Phys. 2003; 57: 944-52.

13. Nath R, Anderson LL, Luxton G, Weaver KA, Williamson JF, Meigooni AS: Dosimetry of interstitial brachytherapy sources: recommendations of the AAPM Radiation Therapy Committee Task Group No. 43. American Association of Physicists in Medicine.Med Phys. 1995; 22: 209-34. Erratum in: Med Phys 1996; 23: 1579.

14. No authors listed: Consensus statement: guidelines for PSA following radiation therapy. American Society for Therapeutic Radiology and Oncology Consensus Panel. Int J Radiat Oncol Biol Phys. 1997; 37: 1035-41.

15. Peeters ST, Heemsbergen WD, van Putten WL, Slot A, Tabak H, Mens JW, et al.: Acute and late complications after radiotherapy for prostate cancer: results of a multicenter randomized trial comparing $68 \mathrm{~Gy}$ to $78 \mathrm{~Gy}$. Int J Radiat Oncol Biol Phys. 2005; 61: 1019-34.

16. Blasko JC, Grimm PD, Sylvester JE, Badiozamani KR, Hoak D, Cavanagh W: Palladium-103 brachytherapy for prostate carcinoma.Int J Radiat Oncol Biol Phys. 2000; 46: 839-50.

17. Ragde H, Korb LJ, Elgamal AA, Grado GL, Nadir BS: Modern prostate brachytherapy. Prostate specific antigen results in 219 patients with up to 12 years of observed follow-up. Cancer. 2000; 89: 135-41.

18. Critz FA, Williams WH, Levinson AK, Benton JB, Holladay CT, Schnell FJ Jr: Simultaneous irradiation for prostate cancer: intermediate results with modern techniques. J Urol. 2000; 164: 738-41; discussion 7413.

19. Izard MA, Haddad RL, Fogarity GB, Rinks A, Dobbins T, Katelaris P: Six year experience of external beam radiotherapy, brachytherapy boost with a 1Ci 192Ir source, and neoadjuvant hormonal manipulation for prostate cancer. Int J Radiat Oncol Biol Phys. 2006; 66: $38-47$.

20. Kwok Y, DiBiase SJ, Amin PP, Naslund M, Sklar G, Jacobs SC: Risk group stratification in patients undergoing permanent (125)I prostate brachytherapy as monotherapy. Int J Radiat Oncol Biol Phys. 2002; 53:588-94.

21. Guedea F, Aguilo F, Polo A, Langley S, Laing R, Henderson A, et al.: Early biochemical outcomes following permanent interstitial brachytherapy as monotherapy in 1050 patients with clinical T1-T2 prostate cancer. Radiother Oncol. 2006; 80: 57-61.

22. Stock RG, Stone NN, Tabert A, Iannuzzi C, DeWyngaert JK: A dose-response study for I-125 prostate implants. Int J Radiat Oncol Biol Phys. 1998; 41: 101-8. 
23. Febles C, Valicenti RK: Combining external beam radiotherapy with prostate brachytherapy: issues and rationale. Urology. 2004; 64: 855-61.

24. Singh A, Zelefsky MJ, Raben A, Lombardi D, Leibel SA: Combined 3-dimensional conformal radiotherapy and transperineal $\mathrm{Pd}-103$ permanent implantation for patients with intermediate and unfavorable risk prostate cancer. Int J Cancer. 2000; 90: 275-80.

25. Zapatero A, Alcantara P, Valcarcel F, de la Torre A, Calvo FA, Algas R, et al.: Preliminary Report of a Multicenter Spanish Trial (GICOR 05) Of Risk-Adapted Androgen Ablation Combined With Dose-Escalation 3D Conformal Therapy For Prostate Cancer: Impact On Early Toxicity. Int J Radiat Oncol Biol Phys. 2003; 57 (Suppl 2): S391-2.

26. Valicenti RK, Winter K, Cox JD, Sandler HM, Bosch W, Vijayakumar S, et al.: RTOG 94-06: is the addition of neoadjuvant hormonal therapy to dose-escalated 3D conformal radiation therapy for prostate cancer associated with treatment toxicity? Int J Radiat Oncol Biol Phys. 2003; 57: 614-20.

27. Gelblum DY, Potters L, Ashley R, Waldbaum R, Wang $\mathrm{XH}$, Leibel S: Urinary morbidity following ultrasound-

Correspondence address:

Dr. Carlos Antônio da Silva Franca

Rua Marechal Niemeyer, 16

Rio de Janeiro, RJ, 22251-060, Brazil

Fax: + $55212266-0449$

E-mail: csfranca@conectacom.net

\section{EDITORIAL COMMENT}

Franca and colleagues report on their experience with low dose rate (LDR) - brachytherapy (BT) and BT combined with external beam radiation therapy (EBRT) for clinically localized prostate cancer in their initial series of 105 patients. It is one of the first SouthAmerican studies evaluating functional and oncological outcomes after LDR-BT. One criticism is clearly guided transperineal prostate seed implantation. Int $\mathbf{J}$ Radiat Oncol Biol Phys. 1999; 45: 59-67.

28. Gelblum DY, Potters L: Rectal complications associated with transperineal interstitial brachytherapy for prostate cancer. Int J Radiat Oncol Biol Phys. 2000; 48: $119-24$.

29. Roach M 3rd, Hanks G, Thames H Jr, Schellhammer P, Shipley WU, Sokol GH, et al.: Defining biochemical failure following radiotherapy with or without hormonal therapy in men with clinically localized prostate cancer: recommendations of the RTOG-ASTRO Phoenix Consensus Conference. Int J Radiat Oncol Biol Phys. 2006; 65: 965-74.

30. Pan CC, Bae K, Hanks GE, Shipley WU, Roach M, Sandler HM. Comparison of Two Types of Biochemical Failures Within the ASTRO and Phoenix Consensus Definitions in Patients Treated on RTOG 92-02 and 9413. Int J Radiat Oncol Biol Phys. 2006; 66 (Suppl 3): S318.

31. Kuban DA, Levy LB, Potters L, Beyer DC, Blasko JC, Moran BJ, et al.: Comparison of biochemical failure definitions for permanent prostate brachytherapy. Int J Radiat Oncol Biol Phys. 2006; 65: 1487-93.

Accepted after revision: July 7, 2007

the small number of patients treated. Consequently, it has to be mentioned that all analysis performed in this study might suffer from a lack of statistical power and historical biases due to the small patient group and the learning curve during implantation in the very first patients. A small number of treated patients might be explained by the fact that LDR-BT is an expen- 
sive procedure and not affordable by the majority of patients in a developing country.

However, the authors have now overcome a learning curve of around 60 treated patients, which, according to the study of Lee and co-workers, are required to achieve adequate D90 and V100 values (1). As a result of this learning process, V100 (mean 82.9\%) and D90 (mean 138.2 Gy) are still below the generally required values. Acute and late toxicity scores were low and not significantly worse when LDR-BT was combined with EBRT. As an end-point, the American Society for Therapeutic Radiation Oncology (ASTRO) definition of PSA failure was still used. Biochemical disease control rates were $79 \%$, $71 \%$ and $52 \%$ in low, intermediate and high risk patients, respectively. Even though the mean number of patients treated per year was obviously lower than 20, these biochemical control rates, at least achieved in the low and intermediate risk groups, are comparable and in accordance to those of larger series from experienced centers (2-4). They document that PSArelapsed patients have a lower D90 than patients with no evidence of biochemical recurrence, underlining the importance of the established values for D90. However, it is critical to compare the oncological results of the present study with large "LDR-BT only" series, as EBRT adds significant therapeutic benefits and the role of combined LDR-BT and EBRT remains to be clarified.

We compliment the authors on their readiness to publish their preliminary and not yet perfect results achieved with a method of growing interest and indications.

\section{REFERENCES}

1. Lee WR, deGuzman AF, Bare RL, Marshall MG, McCullough DL: Postimplant analysis of transperineal interstitial permanent prostate brachytherapy: evidence for a learning curve in the first year at a single institution. Int J Radiat Oncol Biol Phys. 2000; 46: 83-8.

2. Zelefsky MJ, Kuban DA, Levy LB, Potters L, Beyer DC, Blasko JC, et al.: Multi-institutional analysis of long-term outcome for stages T1-T2 prostate cancer treated with permanent seed implantation. Int J Radiat Oncol Biol Phys. 2007; 67: 327-33.

3. Potters L, Morgenstern C, Calugaru E, Fearn P, Jassal A, Presser J, et al.: 12-year outcomes following permanent prostate brachytherapy in patients with clinically localized prostate cancer. J Urol. 2005; 173: 1562-6.

4. Joseph J, Al-Qaisieh B, Ash D, Bottomley D, Carey B: Prostate-specific antigen relapse-free survival in patients with localized prostate cancer treated by brachytherapy. BJU Int. 2004; 94: 1235-8.

Dr. Christian Bolenz

Dr. Lutz Trojan

Department of Urology

University Medical Center Mannheim

University of Heidelberg

Mannheim, Germany

E-mail: christian.bolenz@uro.ma.uni-heidelberg.de 